\title{
Logical Framework Approach to Calabria Sustainable Development: The Intervention Program on School Buildings
}

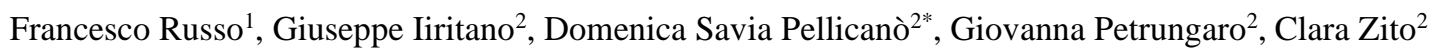 \\ ${ }^{1}$ Dipartimento di Ingegneria dell'Informazione, delle Infrastrutture e dell'Energia Sostenibile, Università Degli Studi \\ Mediterranea di Reggio Calabria, Italy \\ ${ }^{2}$ Regione Calabria, Italy
}

Corresponding Author Email: domi.pel@libero.it

https://doi.org/10.18280/ijsse.100210

Received: 2 October 2019

Accepted: 26 December 2019

\section{Keywords:}

economy, environmental, LFA, planning, school, social, sustainable development, transport

\begin{abstract}
Sustainable development is the main goal set at international, European and Italian level. Calabria Region has addressed the programming activities on the sustainable development articulated in its main components: environmental, economic and social. The program of school buildings implemented by Calabria Region has introduced the obligation of environmental sustainability and seismic certification for all public buildings or financed with public funds, giving a strong acceleration to the process of Calabria building sector in the direction of greater sustainability. This paper presents the case of the school building to underline the strong action made by the Region which consisted of: interventions of seismic adjustment only; unification of all spending programs that guarantee zero bureaucracy and maximum transparency; increase of knowledge through the construction of a database from which to find all the useful information relating to the interventions. In the paper is presented the logical framework approach (LFA) to design a viable path to sustainable development of the school model where, starting from financial resources (input), realizes quality schools (output) in order to pursue sustainable development (goal). The creation of quality schools implies impacts (outcomes) that can be positive or negative. The paper allows to analyze the quality impacts of the school program.
\end{abstract}

\section{INTRODUCTION}

The sustainable development is development that meets the needs of the present without compromising the ability of future generations to meet their own needs. This is the first definition of sustainability introduced by the Brundtland Report in the 1987 [1] in which there is a direct connection among the economic, social and environmental components of sustainability.

Economic growth, environmental protection and social equality are the three main pillars of sustainable development: Development cannot subsist upon a deteriorating environmental resource base the environment cannot be protected when growth leaves out of account the costs of environmental destruction These problems cannot be treated separately by fragmented institutions and policies They are linked in a complex system of cause and effect... No single blueprint of sustainability will be found, as economic and social systems and ecological conditions differ widely among countries [1].

The economic sustainability is mainly the ability to generate income and work for the population livelihood; the social sustainability is the ability to guarantee conditions of human well-being equally distributed by classes and gender; the environmental sustainability is the ability to maintain the quality and reproducibility of natural resources [2].

In 2015, the UN affirmed these principles by strengthening and integrating them into a program of action for people, the planet and prosperity: Transforming our world: the 2030 Global Agenda for Sustainable Development [3].

This document, approved by 193 UN members, has 17 Sustainable Development Goals, (SDGs), 169 targets and 244 indicators.

The 244 indicators are reported in the Global indicator framework for the Sustainable Development Goals and targets of the 2030 Agenda for Sustainable Development [4].

In relation to school buildings, the considered goal is the 4 .

Goal 4. Ensure inclusive and equitable quality education and promote lifelong learning opportunities for all.

The target is 4.a Build and upgrade education facilities that are child, disability and gender sensitive and provide safe, non-violent, inclusive and effective learning environments for all.

The indicator is 4.a.1 Proportion of schools with access to (a) electricity; (b) the Internet for pedagogical purposes; (c) computers for pedagogical purposes; (d) adapted infrastructure and materials for students with disabilities; (e) basic drinking water; (f) single-sex basic sanitation facilities; and (g) basic handwashing facilities (as per the WASH indicator definitions).

EU has considered the environmental sustainability as one of the pillars of programming for next 7 years 2021-2027. The Annex D of the Country Report 2019 [5] set as the Policy Objective 2 A low carbon and greener Europe - Clean and fair energy transition, green and blue investment, circular economy, climate adaptation and risk prevention. 
High priority investment needs: to promote energy efficiency measures, as well as priority investments for renewable energy. Interventions to promote climate change adaptation, risk prevention and disaster resilience are also priorities, in particular, to promote seismic resilience, focusing on public buildings, such as schools and hospitals.

Italy has implemented, at national level, the global challenge launched by Agenda 2030 defining the Strategia Nazionale per lo Sviluppo Sostenibile 2017-2030 (SNSvS) [6] that represents the starting point for the definition of a National Action Plan aimed at outlining a political, economic, sociocultural and programmatic framework, able to face the great themes and challenges that the future holds, with the central focus Sustainable Development.

According the SNSvS it is necessary to work on the construction of sustainable and efficient urban areas and resilient communities and territories, capable of preventing and adequately dealing with natural and anthropic risks, accessible and physically, ecologically and digitally connected, within an organic framework of progress, including cultural and civil society, in which the works of transformation of the territory, infrastructures and buildings ensure not only high environmental and seismic performance but also superior levels of architectural quality, to be achieved through the enhancement of the design activity, and adequate public spaces and green areas are guaranteed and safe.

The planning must therefore integrate all the dimensions of sustainability, which must also permeate the phases of design and management of the buildings, infrastructures, local systems.

In recent years, Calabria has had a great evolution in the programming activities placing the sustainable development as a central theme in line with the UN, the EU and the Italian State. In particular, this is clear in the Economy and Finance Document of Calabria Region 2019-2021 (EFD) [7] and in the Regional Transportation Plan published in 2016 [8].

Through the Sustainable Building Program, Calabria Region has introduced the obligation of environmental sustainability certification for all public buildings or financed with public funds, giving a strong acceleration to the process of evolution of the Calabria building construction sector in the direction of greater sustainability.

This paper presents the "Scuola Sicura" program as a result of an integrated programming in line with the sustainability objectives; a strong action by the Region that made important choices such as: interventions of seismic adjustment only; unification of all spending programs that guarantee zero bureaucracy and maximum transparency; increase of knowledge through the construction of a database from which to find all the useful information relating to the interventions. Through this program, just little less than 800 interventions have been financed or are being financed for a total of approximately 720 million euros. Calabria Region has developed a measure to finance other interventions by providing support to municipalities that have been unable to take advantage of call due to technical or financial difficulties of the administrations. This action aims to complete the programme activating all the seismic adjustment operations in all the schools of the Calabria.

On this basis the objective is to secure all the schools in Calabria and to this end a specific plan provides for the integration of current resources with those of EU programming 21-27, so they are not static but also dynamic integrations.
In this sense the plan for schools can and must become an example for the new programming of the Region on crucial issues; themes that must be agreed with the whole partnership, relaunching its central role.

The school model of Calabria as it is developing can become an EU model to increase the cohesion.

\section{EX ANTE LOGICAL FRAMEWORK APPROACH}

Logical Framework Approach (LFA) is a method for the construction, evaluation and monitoring of a general plan and a specific programme through the identification of the relationships between the inputs and the general objectives [8].

According to the European Commission [9], the LFA is a tool to support the planning process in the three phases of the evaluation: ex-ante, ongoing and ex-post. In the ex-ante evaluation, it contributes to the improvement of the stakeholder participation through the construction of shared objectives, starting from which the plan logic is identified, from top to bottom, up to the definition of the necessary resources. In the ongoing and ex-post evaluation, it contributes to the monitoring of the plan activities, or starting from the verification of the activities, following the plan logic from the bottom up, the pursuit of the plan objectives is verified.

The phases of LFA are two, the analysis and the planning. In the analysis phase, the system is analyzed in the current conditions and a future scenario is hypothesized, selecting the strategies to pursue the objectives, divided into analysis of the stakeholder involved; criticality analysis, with the identification of the current system conditions, the construction of a problems and the identification of the relative cause-effect relationships; identification of objectives, starting from the re-reading from the criticality analysis; identification of strategies. In the planning phase, the plan is developed, articulated in the construction of the Logical Framework (Logical Framework or LOGFrame) in which the elements of the plan and the relative causal links (plan logic) are reported: inputs, activities (strategies), output, specific objectives, general objectives; activity planning and resource planning (costs and inputs).

The results deriving from the analysis phase constitute the basis for the definition of the Logical Framework Matrix (LFM), which supports the actual planning process consisting, as reported in the Regional Transportation Plan of Calabria [8], of [10-12] five lines:

- inputs (constraints), or resources needed to implement the plan;

- activities (strategies), or interventions included in the plan;

- outputs, or products and services to carry out activities under the plan;

- outcomes, or purposes, to pursue, in the medium term, after implementation of the plan;

- goals (objectives), or general objectives, to pursue, in the long term, after implementation of the plan; goals are connected with needs resulting from analysis of the present situation;

and three columns:

- indicators, direct or indirect measurements of the plan elements;

- verification tools, including methodologies and sources of information to calculate the adopted indicators;

- external factors, or events, conditions and decisions that 
could affect the elements of the plan.

The LFM supports the evaluation of plan scenarios, based on the available economic-financial resources, the constraints to be met and the implementation times. The constraints are represented by the regional, national and international regulatory and planning framework that could have effects on transport planning. The implementation times vary with increasing progression, ranging from management strategies (which develop their effects with times commensurate with the implementation of the new organizational structure) to institutional ones (which have different formalization and execution times) up to the investment strategies that take longer to complete, and even longer to carry out their effects on mobility. The assessment of the scenarios must be carried out by means of different approaches with respect to the objectives of the plan, based on the relative economic sustainability (in terms of efficiency and effectiveness), social (in terms of safety, security, accessibility and participation) and environmental through the definition of specific indicators.

LFA and LFM are different: LFA is an analytical process; LFM reports the documented results produced during the analytical process [9].

The implementation of the LFA using LFM is an iterative process, characterized by a defined sequence (Figure 1), from the indication of the general objectives (top-down) to the definition of external factors (bottom-up). All the components are linked by a sequential and rational cause-effect process: starting from the available inputs, if the activities are implemented it is possible to obtain the outputs; if the outputs are obtained it is possible to reach the specific objectives; if the specific objectives are pursued it is possible to reach the general objectives [10].

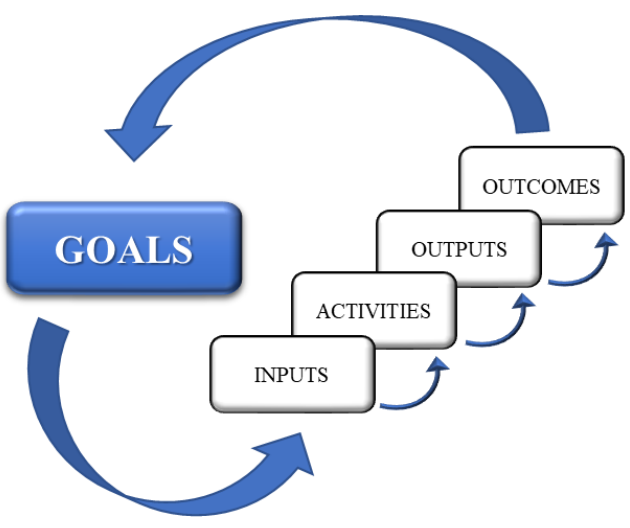

Figure 1. Planning phase

\section{LOGICAL APPLICATION \\ FRAMEWORK \\ APPROACH}

The "Scuola Sicura" program is an example started up by Calabria Region to pursue the goal of sustainable development in line with international and European policies.

The "Scuola Sicura" program is not the only attempt by Calabrian Region to pursue the sustainability goal trying to make the region an example to be followed at European level, but it is part of a wider framework that includes activities about the ports [13-16], the city logistics [2, 17-19] and the Magna Grecia cycle path $[20,21]$.

The LFA is an adequate tool to build a viable path for sustainable development obtainable by the school program.
The school model is a process that, starting from financial resources (inputs), works to make the projects and the realizations (activities), creates quality school buildings (outputs) in order to pursue sustainable development (goal). This implies the impacts (outcomes) that can be positive or negative.

The LFA sequence to be controlled is therefore inputs, activities, outputs, outcomes and goal; considering the internal factors, the external factors and all the conditions of uncertainty.

In the case presented in the paper, two different paths are implicitly reported:

- the first one relative to the choice preliminary made with the simulated results;

- the second one relative to the real results obtained at today.

In this way goals and outcomes are modelled staying in an ex-ante situation; outputs, activities and inputs are partially ongoing, partially ex-ante and partially ex-post. Then the sequence living from goals and outcomes will be presented, considering after the goals, the specific choices made and activated to push the process.

A new interaction starts after the first one.

\subsection{Goals}

Calabria Region, in line with the objectives set by the UN, EU and Italian State, aims at sustainable development of the territory in its economic, social and environmental components.

Sustainable development is the best solution to take to get Calabria out of the marginal condition it has been in for a long time.

The school represents a crucial node to mark how the realizations (outputs) can aim at sustainability (goal). The evaluation of the social, economic and environmental impacts that can be obtained is a decisive element that makes Calabria among the first European regions.

\subsection{Activities}

The start point of school program can be analyzed considering three crucial questions: the seismic question, the funding question and the knowledge question.

The seismic question is important as Calabria has a very high seismic risk, considering that Italy has about 3,000 school buildings in seismic zone 1 (the most dangerous and subject to major earthquakes) and of these $50 \%$ are in Calabria; the rest of the Calabrian school buildings is in zone 2. So, 19,000 schools in zones 1 and 2 make safety in schools a national problem.

Calabria Region has given a crucial technical-political choice, it wants that the structural interventions in school buildings must aim at seismic adjustment or demolition and reconstruction and not just improvement. These measures make schools fit to withstand the earthquake.

The funding question is linked to the large amount of funds of various origin (Regional, National or European) available. POR, FSC, annual MIT funds, annual MIUR funds, regional budget funds, etc. Different acronyms indicate the different types of fund. Each of them has different rules for assignment, management, certification, etc. It's a real jungle of financial sources where local administrations and technical designers 
have great difficulty in finding their way and often, they fail to understand how different types of public funds should be employed.

The Italian regions have historically prepared a call for tenders for each fund in which municipalities, provinces, metropolitan cities and other titled bodies could participate. This means managing multiple calls each year, managing multiple commissions, having multiple rankings. For Municipalities and other Bodies, this means preparing a project for each call, following the announcement, checking whether it is financed or not, understanding if it is not financed, why this happened, and so on. A heavy bureaucratic machine.

In this situation there could be the extreme condition that a generic Municipality could be the first of the unfunded in all the rankings.

Calabria Region has given a technical-political response absolutely against the trend, a single call and all the resources that come from the various funds, always scrolling through that call, until the end.

With this decision the bureaucracy was zeroed: Municipalities and the others have full transparency and can concentrate on the project quality and not on the formal path. An eligible project will be funded as soon as resources are available.

The unique ranking eliminates shortcuts, fogs suddenly, opens the windows. This guarantees maximum transparency.

The knowledge question is linked to the need to have a census of all the buildings in order to have a global knowledge of the building assets. In 1996 was introduced the school building register used to gain knowledge of the entire building assets. The Ministry of Education is the subject that carries out and updates the register. In 2011, Calabria Region acquires the platform. In 2014 the National System of the School Registry Offices (SNAES) was established. In this system, each building has a sheet which identifies the description of the building, its techno-dimensional features, the current situation and its functionality.

If a building has the completed sheet, the building is with green SNAES.

Calabria Region imposes an important clause: each Municipality to present the request for funding for an intervention must load all the school buildings of the Municipality on the regional register.

In August 2015, only one building had green SNAES; in November 2016: 345 buildings, in November 2017: 1,995 buildings, in December 2018 the $96 \%$ of the buildings surveyed are with green SNAES.

\subsection{Inputs}

The "Scuola Sicura" inputs are the financial resources put in place to carry out the interventions.

Specifically, there are approximately 775 million euros. To date, at least 12 different European, National and Regional financial sources are involved in schools, including POR, FSC, multi-year MIURs, multi-year MIT, etc. The funds are available from sources such as the FSC 2014-2020, the POR Calabria 2014-2020, LR 48/2018, EIB Loans, the Civil Protection Fund and other national sources. There are also 175 million euros in the process of being awarded coming mainly from European and National measures, e.g. PON School, Stability Law 2018, next POR, etc.

A total of 600 million euros is allocated today to the Calabria "Scuola Sicura" program and - more or less - other
120 million euros are in course of definition and for which, in few months, the projects will be available; other 55 million euros will be from the POR 2021-2027.

The transformation of inputs into outputs, that is from resources to realizations, has multiple impacts. The qualitative leap is made by analyzing not only the investments (inputs), if they have been made, if the times have been respected; but checking if the finished works and outputs (outputs) are of quality. Input and output controls allow to be in line with the best European regions.

\subsection{Outputs}

The "Scuola Sicura" outputs are the realizations of the interventions consisting in the school seismic adjustment. There are about 650 interventions in progress, in some schools the works are finished, in others they are being carried out; another about 170 are to be implemented with resources being awarded. In total there are about 820 interventions funded and to be financed at today in Calabria Region.

Calabria is first in Italy for the number of buildings on which it is intervening.

A summary schedule with the time required to complete the work and therefore the cost is attached to each financed operation. Therefore, for each intervention, it is possible to know an estimate of how much expenditure is made each year starting from the signing of the agreement. It is therefore possible to estimate the total expenditure of each year and then to calculate the outcomes.

\subsection{Outcomes}

According to an analysis made by the European Commission [5], in 2016, the cost faced by Italy for seismic events was around EUR 22 billion on infrastructure, businesses, public and residential buildings. In this context, though Calabria is a region with high seismic activity, it performed vulnerability checks on only $2 \%$ of school buildings.

The school model produces impacts on sustainability (goal) that can be divided into social, economic and environmental impacts.

Among the social impacts, one of the most important is the risk reduction [22]. The risk is a typical probabilistic variable depending on:

1. the danger or on the probability of occurrence of an event;

2. the vulnerability or the probability of an element of the system to resist (or not) to the event;

3. the exposure of people and goods in the system.

Concerning the earthquake, it is not possible to act on the probability of occurrence; the exposure can be modified through evacuation tests, simulations, specific behavioral lessons. The vulnerability is the one component that can be improved, thus reducing the risk, by making the seismic adjustment of school buildings.

School buildings have the highest level of population concentration over time.

About 280,000 pupils live a large part of the day in the school buildings of Calabria; moreover, there are about 32,000 teachers and about 10,000 employees of non-teaching staff. Therefore, more than $16 \%$ of the population of Calabria lives in schools for at least $4 / 5$ hours a day for $5 / 6$ days a week, for 40 weeks a year. 
No other territorial area has such a large concentration, not even residential construction. The latter has a presence of population that is evidently longer over time, but the density is significantly lower than the exposure and therefore the risk is reduced compared to the school. There are also other high concentrations but for specific points and for reduced time bands, such as for example the stands of sports facilities, cinemas.

To strongly reduce the societal seismic risk [22], it is necessary to act on the vulnerability. Defining the societal risk level as the total risk level associated with the earthquake to the Calabria population.

Another social impact is the one on employment. Some multiple statistical analyzes assess the employment impact of the public investments in the various sectors. These statistical surveys state that 100 million invested in the construction sector generate about 800 direct employees, 700 indirect employees and 600 induced. That is about 2,100 people employed.

It is to consider that the adjustment or the demolition and reconstruction of a school building are "labour intensive", the real employed are certainly more than the 2,100.

Moreover, the multiplicative effects as the workers who build the drills, the trucks, and then their induced, etc., are not considered; there are about 1,000 employees involved, called to work in Northern Italy or in a industrialized European area due to these effects induced by the school model.

A data estimate states that in Calabria there could be about more than 4,800 employed in 2020, 5,800 employed in 2021 linked to "Scula Sicura" program.

Considering that in Calabria the construction sector has about 32,000 employees on average, the result is an increase between 15 and $20 \%$ of employment in the sector alone with school buildings.

The economic aggregated impacts of the Calabria school program are important. To simplify it is possible to aggregate all the sources into two funding sets.

The first set regards the reliable sources, with agreements already signed or in progress, planned by the Region, with regional, state and European money.

In March 2019, about 650 interventions were started for about 600 million euros.

The second set concerns the certain state and regional sources, but to be attributed. This set contains the PON funds, the funds of the stability law, the funds of the urban agenda and the funds of the law 289 of 2002 which were to be awarded in the summer of 2018, but which with a simple amendment in a national law were moved to the end of 2019 as allocation and attribution.

The total of these resources is about 175 million euros. Considering an average amount per project a little bit more than 1,000,000 euros, 170 interventions are estimated.

The school program has impacts on the Calabria GDP too. The components of the GDP linked to the "Scuola Sicura" program can be estimated through the impact of the school model on the absolute value of GDP.

The GDP growth in Calabria was $2 \%$ in 2017/2016 [23] for more or less 600 million euros.

The investments made with the school model can be estimated at 230 million euros in 2020 and at least 280 million euros in 2021.

To directly calculate the impact on the absolute value of GDP, assume that GDP over the next 2 years (2020-2021) has the same value as 2017 . The impact of school interventions is estimated at $0.7 \%$ in 2020 and $0.8 \%$ in 2021 .

Regarding the environmental impacts, Calabria has followed the ITACA Protocol [24].

The areas of evaluation for the ITACA protocol are:

- site quality;

- resource consumption;

- environmental loads;

- indoor environmental quality;

- quality of the service.

Specific classes are identified for each area

Considering the resource consumption, the interventions are aimed at three classes of energy impacts:

- Energy required during the building's life cycle (highlighting the non-renewable);

- Energy from renewable sources (for thermal uses or produced for electrical uses);

- Envelope performance (energy for heating and cooling)

The ITACA protocol allows to verify the performance of a building with reference not only to consumption and energy efficiency, but also taking into consideration its impact on the environment and on the health of users.

The ITACA protocol allows to assign a score between -1 and +5 to the interventions proposed in a project. 0 indicates no energy improvement, 5 the maximum possible.

In the regional rankings for schools up to the value of 1 no additional point is given in the funding ranking. This led the designers and the engineering to push on the environmental sustainability of the project.

The assessment of sustainability follows the evolution of the intervention from the various phases of the project to the final realization [25].

It is interesting to note that in the second ranking the average of the scores in prevalence is 1.6 , with a minimum value of 1 and a maximum of 4.3 indicating a high environmental sustainability.

These values indicate the quality of new and refitted buildings.

In this way the goals are fully pursued.

\subsection{New perspective new iteration}

Recently Calabria Region has tested a new simpler method for the funding allocation related to the seismic adjustment of school buildings through the approval of the resolution of the regional govern n. 300 of 1 July 2019 [26]

Thanks to the Calabria Regional Financial Law 48/2018 all the projects, evaluated as eligible for the previous regional calls, have been funded.

Moreover, Calabria Region [26, 27] has approved a ranking list of the risk level of the buildings where seismic adjustment interventions are not in progress, using a simplified methodology. The ranking establishes the priority with which buildings must be seismically adjusted. This has been possible only after completing of the activity related to regional SNAES, carried out as described above, employing a simplified but rapid methodology [27].

Calabria Region has set a "zero point" in school buildings programming, starting to abandon of the traditional bottom-up programming and moving towards the top-down programming. Highlighting that all proposed projects will be funded.

This will be done through three parallel actions [26]. 
First of all, a new call will be published for all local administrations having a project ready (or that can prepare it in a short time) that they were not able to present to the previous calls (for various reasons: organizational weaknesses or lack of funds for design).

The second activity will consist in a call in which the regional administrations will grant the funds for the design of the seismic adjustment in school buildings (with priority to the level of risk assessed by the Region on all school buildings [27]).

And finally, the third activity will consist in a call through which the Region will directly select highly qualified technical designers in the field of buildings seismic adjustment, creating a list to which all local administrations will be able to design intervention.

This third activity will allow local administrations to design intervention on building school, with less bureaucracy, taking technical designers from regional list, achieving three important results: 1) reduction of the time needed to design 2) higher quality in projects 3 ) enhancement of the best local professionals

By closing these three new calls, Calabria Region will be able to avoid publishing of new calls for seismic adjustment of school buildings in the future. Every local administration (even the most disorganized) will be able to access the funds. Whenever a local administration has a valid project (which can be prepared using the funds for the design and regional list of qualified technical designers) it will present the application to the Region that will finance it following a FIFO (First in First Out) method.

\section{CONCLUSION}

The "Scuola Sicura" program has shown that a Region can be among the first in Europe even starting from highly disadvantaged conditions.

More generally, considering economic outcomes on GDP, there is a condition of full reversibility for region in disadvantaged conditions as recently happened for the regions of East Germany, and more in general East Europe.

The "Scuola Sicura" program aims to complete all seismic adjustment operations in all the school buildings in Calabria and it can be pursued with the European and national resources of the next programming provided that the choices made so far are confirmed.

The paper also described the program recently launched by Calabria Region with the approval of the resolution of the regional govern n. 300/2019.

With this program the second iteration is performing with the final target of all school buildings in line with the best international standard regarding seismic and environment to sustainability.

\section{ACKNOWLEDGMENT}

The Governor of Calabria from 2014 to 2020 has been Mario Oliverio.

\section{REFERENCES}

[1] WCED - World Commission on Environment and
Development. (1987). Report of the World Commission on Environment and Development: Our Common Future. https://sustainabledevelopment.un.org/content/documen ts/5987our-common-future.pdf.

[2] Russo, F., Pellicanò, D.S. (2019). Planning and sustainable development of urban logistics: From international goals to regional realization. WIT Transactions on Ecology and the Environment, 238: 5972. https://doi.org/10.2495/SC190061

[3] United Nations. (2015). Transforming our world: The 2030 Agenda for Sustainable Development. https://sustainabledevelopment.un.org/content/documen ts/21252030\%20Agenda\%20for\%20Sustainable\%20De velopment $\% 20$ web.pdf.

[4] United Nations. (2018). Global indicator framework for the Sustainable Development Goals and targets of the 2030 Agenda for Sustainable Development. https://unstats.un.org/sdgs/indicators/Global\%20Indicat or\%20Framework\%20after\%20refinement_Eng.pdf.

[5] European Commission. (2019). Commission Staff Working Document. Country Report Italy 2019. https://ec.europa.eu/info/sites/info/files/file_import/201 9-european-semester-country-report-italy_en.pdf.

[6] Ministero dell'Ambiente e della Tutela del Territorio e del Mare. (2017). Strategia Nazionale per lo Sviluppo Sostenibile. https://www.minambiente.it/sites/default/files/archivio_ immagini/Galletti/Comunicati/snsvs_ottobre2017.pdf.

[7] Regione Calabria. (2017). Documento di Economia e Finanza della Regione Calabria (DEFR) per gli anni 2018-2020. Adottato con DCR 277/2017: Nota di aggiornamento del Documento di Economia e Finanza della Regione Calabria (DEFR) per gli anni 2018-2020 (Paragrafo 6 del principio applicato della contabilità allegato 4.1 e art. 36 del decreto legislativo 23 giugno 2011, n. 118).

[8] Regione Calabria. (2016). Piano Regionale dei Trasporti. Adottato con DCR 157/2016: Adozione della proposta di Piano regionale dei trasporti - Piano Direttore e presa d'atto dei relativi documenti previsti dalla procedura di valutazione ambientale strategica/valutazione di incidenza.

[9] European Commission. (2004). Project Cycle Management.

http://ec.europa.eu/europeaid/multimedia/publications/p ublications/manualstools/t101_en. htm.

[10] Russo, F., Rindone, C. (2007). Dalla pianificazione alla progettazione dei sistemi di trasporto: processi e prodotti, Ed. Franco Angeli.

[11] Russo, F., Rindone, C. (2008). Safety of users in road evacuation: The logical framework approach in evacuation planning. Proc. of Urban Transport XIV, Urban Transport and the Environment in the 21st century, Brebbia C.A. (ed.), WIT Press, Southampton, pp. 751 760. https://doi.org/10.2495/UT080721

[12] Russo, F., Rindone, C. (2011). The planning process and logical framework approach in road evacuation: A coherent vision. Safety and Security Engineering IV, WIT Transactions on the Built Environment, 117: 415425.

[13] Regione Calabria. (2018). Delibera di Giunta Regionale n. 308 del 13/07/2018 "Patto per lo sviluppo della Regione Calabria. Linee di indirizzo per la programmazione di interventi nei settori prioritari 
sistema portuale - porto di Gioia Tauro e sistema portuale. Porti nazionali e regionali. Rimodulazione indirizzi di cui alle delibere di giunta regionale nn. 412/2016 e 413/2016. Presa d'atto sottoscrizione accordo tra amministrazione a norma dell'art. 15 della L. 241/1990 e ss.mm.ii".

[14] Regione Calabria. (2018). Delibera di Giunta Regionale n. 309 del 13/07/2018 "Patto per lo sviluppo della Regione Calabria. Linee di indirizzo per la programmazione di interventi nel settore prioritario sistema portuale. Porti nazionali e regionali. Rimodulazione indirizzi di cui alla Delibera di Giunta Regionale n. 412/2016. Procedura di selezione per interventi da ammettere a finanziamento mediante avviso pubblico a valere sulle risorse del Programma Operativo Calabria FESR/FSE 2014/2020 azione 7.2.2 - Potenziare infrastrutture ed attrezzature portuali e interportuali di interesse regionale. Destinazione risorse Fondo di Sviluppo e Coesione 2014/2020 e Piano di Azione e Coesione 2014/2020".

[15] Russo, F., Rindone, C. (2019). Nautical tourism and regional population: The Italian case. WIT Transactions on the Built Environment, 187: 251-263. https://doi.org/10.2495/MT190231

[16] Rindone, C. (2019). Coastal and nautical tourism: the case of Italian Regions. WIT Transactions on the Built Environment, 188: 129-139. 10.2495/CC190121

[17] Regione Calabria. (2017). Delibera di Giunta Regionale n. 391 del 10/08/2017 "Piano Regionale dei Trasporti Attuazione programma di attuazione city logistics misura 2.5 del PRT".

[18] Calabrò, T., Iiritano, G., Trecozzi, M.R. (2019). City logistics: case of Calabria Region. WIT Transactions on The Built Environment, 188.

[19] Iiritano, G., Trecozzi, M.R. (2019). Activities training on city logistics: Case of Calabria Region. WIT Transactions on Ecology and the Environment, 238: 161171. https://doi.org/10.2495/SC190151
[20] Regione Calabria. (2019). Delibera di Giunta Regionale n. 70 del 19/02/2019 "Protocollo d'intesa per la progettazione e realizzazione della ciclovia della Magna Grecia. Approvazione dello schema di protocollo e nomina del delegato alla sottoscrizione".

[21] Regione Calabria. (2019). Delibera di Giunta Regionale n. 91 del 5/03/2019 "Protocollo d'intesa per la progettazione e realizzazione della ciclovia della Magna Grecia - riapprovazione dello schema di protocollo con le modifiche proposte dalla Regione Basilicata. modifica alla DGR n. 70 del 19/02/2019".

[22] Russo, F., Vitetta, A. (2006). Risk evaluation in a transportation system. International Journal of Sustainable Development and Planning, 1(2): 170-191. https://doi.org/10.2495/SDP-V1-N2-170-191

[23] SVIMEZ. (2018). Rapporto Svimez 2018 l'economia e la società del mezzogiorno, Sintesi.

[24] Regione Calabria. (2017). Protocollo ITACA, Regione Calabria, Edifici Pubblici. http://itaca.calabria.iisbeitalia.org/sites/default/files/Prot ocollo_ITACA_Reg.Calabria_Ed.Pubblici_2017.pdf

[25] Petrungaro, G., Corasaniti, B. (2019). Sustainable Building Program of the Calabria Region. First results. Sustainable Built Environment Conference. May 16-17 $7^{\text {th }}$ 2019, Scilla, Italy. In Press.

[26] Regione Calabria (2019). Delibera di Giunta Regionale n. 300 dell'1.7.2019. "Atto di indirizzo per la definizione del Progetto Strategico "SCUOLA SICURA", finalizzato all'aggiornamento del Piano regionale triennale 2018-2020 in materia di edilizia scolastica".

[27] Petrungaro, G., Iiritano, G., Caruso, M., Di Ludovico, M., Prota, A. (2019). Una procedura per la valutazione speditiva del rischio sismico degli edifici scolastici. L'applicazione agli edifici scolastici della Calabria. XVIII Convegno ANIDIS L'ingegneria Sismica in Italia. Ascoli Piceno 15-19 September 2019. In press. 